\title{
Social Networks and Social Ties: Changing Trends among Urban Dwellers in Bangladesh
}

\author{
Ahsan Habib' ${ }^{1}$ Fahmida Hossain², Tahsina Ferdous ${ }^{3}$, Khalilullah Muhammad Bayezid² \\ ${ }^{1}$ Department of Sociology and Anthropology, Green University of Bangladesh, Dhaka, Bangladesh \\ ${ }^{2}$ Department of Sociology and Anthropology, Asian University of Bangladesh, Dhaka, Bangladesh \\ ${ }^{3}$ Department of Anthropology, Jagannath University, Dhaka, Bangladesh \\ Email:ahbd44@gmail.com
}

How to cite this paper: Habib, A., Hossain, F., Ferdous, T. and Bayezid, K.M. (2018) Social Networks and Social Ties: Changing Trends among Urban Dwellers in Bangladesh. Open Access Library Journal, 5: e4604. https://doi.org/10.4236/oalib.1104604

Received: April 17, 2018

Accepted: May 18, 2018

Published: May 21, 2018

Copyright (C 2018 by authors and Open Access Library Inc.

This work is licensed under the Creative Commons Attribution International License (CC BY 4.0).

http://creativecommons.org/licenses/by/4.0/

\section{(c) (i) Open Access}

\begin{abstract}
This paper entitled "Social Networks and Social Ties: Changing Trends among Urban Dwellers in Bangladesh" discussed the impact of using social network sites on social ties. The main aim of the article is to reveal how internet and social networking sites reshapes our social relations especially in urban settings. The study followed qualitative way of analyzing social relations and its dynamics. Using empirical data, the article reveals how technological development is changing the contemporary world very rapidly. Changes are taking place in all spheres of life and ultimately these situations change our own society, conventional social thinking patterns and cultural beliefs. The internet is offering new forms of social relations and ties in both private and public sphere through social networking sites like-Facebook, Skype, Twitter, Viber, WeChat, WhatsApp and Imo etc.-that affect the pattern of our day-to-day interaction and relationships within families, communities and society at large. For these changes, human behavior is also changing and therefore, the study is becoming more important in the preset interpersonal relationship. Our contemporary way of living is demanding too much time away from natural social relationships because of technological advancement which is playing a major role for these changes and has a definite consequence on the social and cultural area of Bangladesh.
\end{abstract}

\section{Subject Areas}

Sociology and Anthropology

\section{Keywords}

Social Change, Social Ties, Social Networks, Technology, Facebook 


\section{Introduction}

The role of technological development in society has been an interesting area and an important intellectual issue for academia. In past two decades, technology bursts out like an explosion, which in consequence enables the spread out of globalization through technological innovation; trends of society, social institutions and social ties cannot escape from this enchanted wave. Continuous expansion of Internet comes to grow a ubiquitous networks society [1] (Houghton \& Joinson, 2010). According to Bangladesh Telecommunication Regulatory Commission (BTRC), the total internet user of the country is to a little over 80 million. The number of mobile phone users in December last was over 145 million. Most of the subscribers use mobile internet and their number was about 75 million [2] (BTRC: Half of the population uses internet, 2018). It is around 50\% of mobile internet and 10\% of ISP bandwidth spent on browsing Facebook in Bangladesh [3] (Halim, 2017). It would be more if we take into account of other sorts of social media like Imo, WhatsApp and Viber. Technical advances of Internet and mobile technologies have promoted new forms of social communication [4] (Rheingold, 2002). Facet of social media emphasizes on changing relationships, interestingly it changes the foundation of the ways we relate to. The increased prevalence and use of information communication technologies (ICTs) have transformed peoples' live in terms of how they work, form, and maintain social relations as well as plan and use leisure time [5] (Anawati \& Craig, 2006).

In Bangladesh, Technology and social media has changed the inter-personal relationship and behavior from family to society. Social ties, social media and social networks are offering various forms of changing trends in this society. Now, the influence of technological development is changing the present-day world very rapidly [6] (Mortimore, 2001). Changes are taking place in every spheres of life and ultimately changing the social and cultural belief systems overtly and covertly. Social network is the one which is playing a major role for these changes-both in high and low income country [7] (Crimmins, Preston, \& Cohen, 2010). The introductions of satellite television and internet service are the dimensions of the technological advancement that have a definite effect on the social and cultural area of Bangladesh. For these changes, human behavior, social ties and social relationships are also changing and therefore, the study of changing trends in society is becoming more important in the present global world. The process of globalization inevitably creates a technologically advanced world, where the principles of family relationships are undermined by the dominance of global culture [8] (Kaul, 2012). The "unlikely" becomes "likely" and the "unusual" becomes "usual" and vice versa devoid of local customs through the imposition of diffusion of non-native culture. Perhaps, the most important far-reaching effect of this duo of globalization and technological innovation is the commercialization of culture [9] (Robbins, 2008).

The development of information and communication technologies enables 
dynamic social interaction through computer and smart phone mediated communication devices. It is easy to define technology when it is understood as an instrument or a tool, appeared in the form of conjunction of some machinery parts. The vivid existence of the technology helps us remarking wherever it extends to our lives and whatever changes it brought. However, it has become more difficult with the spirit of modernity that put the technology itself in its end instead of fulfilling human needs. The new technology (technologies that are perceived as capable of changing the status quo, e.g. Facebook, twitter, Whatsappetc) has made it almost impossible today to grasp the general notion of technology disperses in our day to day lives. Advancement of new technology in the form of communication and network has fathered huge changes to our daily lives including the emergence of different human groups and multifarious networks grounded through computer-mediated soft technologies, e.g. the Internet [10] [11] (Ellison, Steinfield, \& Lampe, 2007) (Watt, Lea, \& Spears, 2002). The recent changes in communication technologies, especially with the emergence of SNSs (Social Network Sites), change in our interpersonal relationship especially the romantic relationship in our country.

\section{Background}

The people of Bangladesh, specially the higher class, got the opportunity to use Internet for the first time in 1996 [12] (Chowdhury, 1996). Gradually Bangladeshi people get introduced with different usages internet, though a large number of people do not have access to internet till today. Social networking sites are used more than any other applications today by the internet users of Bangladesh. In past two decades, technology burst out like an explosion, which in consequence enables the spread out of globalization through technological innovation; and a Social tie, which is one of the major sectors of social interaction, cannot escape from this enchanted wave. This phenomenon has a global notion that is prevalent in almost every society around the world and Bangladeshi societies are no exception. Due to the modern urban revolution and technological development social ties has been going through many important organizational and functional changes.

Technology experts embrace the use of networked communications technologies and are naturally inclined to find them to be useful in social relations, so it is no surprise to see the high level of agreement that the Internet is a tool that gets positive results. Still, quite a few people took advantage of the opportunity to provide written elaborations in which they pointed out many negatives, and they shared other incisive observations.

The internet has been embraced globally at a remarkable speed because of its capabilities for communication and connection-for creating, cultivating, and continuing social relationships. One great advantage is that email, social networking tools and other apps allow people to maintain greater and wider social networks and learn more about those in their networks. Richer social relations 
emerge from this greater awareness. Another advantage is that, it is much easier now to build communities on the fly via personal broadcasts. All these trends will continue to hold strong over the next decades.

Bangladesh is no longer identical to its traditional form but is explored to be with new norms, roles and values. The new forms are the results of changes like the growth of communal living arrangements in cities and rural areas across the country, emergence of new dimension of social ties and social relationship. Due to impact of globalization in Bangladesh, the basic structure of the family has not changed drastically but internal functions, such as sex roles and intimate relationships have been redefined gradually [13] (Akhter \& Palit, 2016). Family, kinship and social ties are no longer the dominant social institutions in the social order, and these have lost many of their traditional functions to competing institutions.

\section{Changes and Understanding of Social Ties and Social Networking}

Usually the determination of social ties follows a standardized procedure asking individuals who they consider a friend, approach for professional help, or communicate with on a regular basis. However, social ties are rather elusive to quantify, especially for a large sample of subjects over prolonged periods of time [14] (Wuchty, 2009). According to the Oxford English Dictionary, Social Media is defined as: "Websites and applications that enable users to create and share content or to participate in social networking" and Social Networking is defined as: "A platform to build social relations among people who share interests, activities, backgrounds or real-life connections." On the other hand Donath and Boyd said "social networking sites are on-line environments in which people create a self-descriptive profile and then make links to other people they know on the site, creating a network of personal connections" [15] (Donath \& Boyd, 2004).

Social Media is playing a significant role in the life of people in Bangladesh. Networks have become the most basic elements of human civilization since everyday life would be unimaginable today without modern transportation, public utilities and communication networks. Although the scientific investigation of social networks has been going on for some decades, it has only recently become such a popular area of research. High-configured computers have made it possible to analyze various natural systems (e.g. cells) and social phenomena (e.g. the use of the Internet) which can be interpreted as networks, on the basis of measurable indicators. Millions of people use the network of the Internet on a daily basis that is why it has been found to have a fundamental effect on the social system of relationships, on formal and informal structures, social capital and the development of trust.

With the development of the information society and its technical expertise, the subsystems of society are operating more and more like a network. Instead of natural resources, after the second half of the twentieth century, information and 
access have become the most important economic and social organizing forces. From the 1960's information has been produced, processed and distributed with the help of modern information and communication technologies [16] (Internet Usage Statistics, 2017).

A social network is a structure made up of individuals with a commonality like friendship, interest, relationship, knowledge, and experience or belief system. In the past, social networks have been limited to one's geographical location, social standing or ethnicity. Today, with the global, inter-cultural and inter-general composition of sites such as Facebook, Skype, Twitter, Viber, WeChat, WhatsApp, social networks have become far more diverse and dynamic [17] (Ofcom, 2008). A social network can be seen as a positive resource that can influence activity and productivity of the individual or the collective. In the present time social network sites provide simple, inexpensive ways to organize members, arrange meetings, spread information, and gauge opinion. As more system emerges, there will be greater capacity for groups to organize and participate in collective action, a hallmark of civil society.

Social network sites have the potential to fundamentally change the character of our social lives, both on an interpersonal and a community level. Changes in interaction patterns and social connections are already evident among young people, who are the heaviest users of these sites. In the past few years, social network sites have become integrated into the daily practices of millions of users, most visibly those of young people, but usage is rapidly spreading to older people and other groups.

Getfer [18] (Gefter, 2007) asserts that, the distinction between real lives and online is no longer clear-cut as the people making up online and offline interactions are largely the same. Divisions between online and offline social activity are not necessarily evident in contexts of Social media, such as Facebook. Key issues to emerge from this study include the value of the Facebook site enabling users to connect with people from both their past and their present and maintaining contact with close friends, even the most distant of acquaintances. In this respect, Facebook is used as a supplementary tool to communicate, it does not replace face-to-face or telephone activity. It enables cheap, casual communication with people who would otherwise have lost contact, particularly those without the time or inclination to engage in more formal, traditional forms of communication [19] (Miller, 2011).

\section{Research Question}

From the above discussion we perceive the multifaceted notion of changes in the society took place in the last couple of decades. In the context of social networking, these changes are evident both in external and internal aspects of social ties and social relationships. In this narrow scope of the current study we have formulated three major objectives: to what extent the increasing level of social networking influence the nature of change in private sphere and in public sphere. 
And, does it redefines or transforms the notion of public vs. private dichotomy?

\section{Methodology}

The methodology we use is qualitative due to the nature of the research topic and objectives. Social ties itself is very sensitive issue and it assumes more sensitive forms where it is linked up with the present changing nature of technology and globalization and therefore quantitative methods cannot find hidden issues that might be associated. The study is based on three important areas Uttara, Malibagh, Mogbazar of Dhaka city. The respondents were selected by using purposive sampling technique from the study sites in order to gain in-depth information about their changing social ties and social relationships. The study uses both primary and secondary sources to perceive the changing notion of society. Using qualitative techniques like in-depth interview, case study, observation to collect and interpret data, the study highlights the forms of changing trends of society on the base of social ties and social networks.

\section{Major Findings and Discussion}

Major findings of this study will be discussed in two points-private sphere and public sphere, where the changing trends of social ties as well as networked will be in focus.

\subsection{Private Sphere}

Family and relationship evolves in accordance with the changes in time and technology. The conventional family system that existed fifty years ago does not exist today. Due to globalization, family relationship especially in the urban areas has been changing; in this research we have found that family relationship in a city like Dhaka has adopted a new changing trend. Women in urban or industrial areas are to involve themselves in different types of income generating activities. As a result, dual workers' families in urban areas are increasing [20] (Castells, 2006).

In Bangladesh, it could be noticed that there is a growing change in traditional family structure and conventional family ties. We are observing a rapid structural shaping and socio-cultural shifting in the Bangladeshi society today. Let us take a quick look at the lives of changing family dynamics. The following case studies are excerpts and insights by fathers, mothers, daughters and husbands on how their families have changed over the years. A 62 years old woman Sayeda interprets the changes in literary way in case-1 and Mostofa (50) shares in case-2:

Case: 1

In the year of 1980, when the dazzling summer sun flows from side to side of the windowpane, Dadima (grandmother), Ma (mother) and Chachima (paternal mother) are fast snoozing in afternoon as we compose our way to the roof for fulfilling our mission-steal all the aamerachar (pickled man- 
goes), meanwhile bhaiya (brother) gathers all cousins and boys of the area for a game of "gali (street) cricket".

All things are timed accordingly including stealing and gaming until father back home. Because, we all knew that, father, the head of the household returning home means no more games would be allowed. We were used to put an end to all games.

Now, in 2018, Sayeda is a mother of one son and a daughter. She noticed when her husband came to the house after whole day working in office and finds her daughters engrossed in their smart phones. She said, we are influencing our children to go to outdoor but nothing change. Even in today, the children do not have any fear to father like we did in our childhood. On the other hand, they are pressurizing various demand and wants to their father.

\section{Case: 2}

Mostofa is a man grew up in his village-home. Now he is working as an executive officer of a multinational company. He has two teenage daughters of 14 and 18, who are studying in one of the renowned English medium schools of city. His daughters early childhood were past in village. At present, they are mostly busy with the study and they are not used to go to their grandparents' house. They made video call to communicate with them and most of other village relatives. They have passing their leisure time with smart phones, gaming and browsing social networking sites like facebook, twitter and so on.

As Mostofa said, "I always want my children to go out to play, to be in touch with nature, but their days are occupied with their smart phones, TVs, gaming consoles, visits to shopping malls and restaurants."

Much has changed since those early days of both Mostofa and Sayeda. Nuclear families have replaced joint families. Spontaneous and cognitive loves and affections have been replaced with artificial, technological hi, hello, what's up. Families these days are seeing a drastic change. As both parent's go to work, and more and more people move to urban areas, the social structure and our dynamics with families has also taken a changed.

Marriage pattern has changed also and self and self-selected marriage/affair marriage is replacing the long-practiced and socially welcomed arranged marriage system. Husbands have shown a positive view to the employment of wives and even they have taken positively the late return of their wives from service. Wife's influence in family has increased because of her economic contribution and her participation in decision making process has become more evident. Patriarchal attitude of life is declining day-by-day as well as urban parents have been modifying themselves to understand the demand of changing time and to keep pace with the new circumstances. Parents are giving priority to their children's taste, opinion, choice etc. 
The best test of how a person uses their emotional intelligence may be in their romantic relationships. In romance, feelings are strong and personal, and it is easy to feel hurt, rejected, disappointed etc. Cognitive, intellectual intelligence alone is not enough. Also, a person could have a high level of innate emotional intelligence, but if they grew up in an emotionally unfulfilling, unhealthy or dysfunctional family, culture or society, they could still have very poor relationship skills.

\subsection{Public Sphere}

The net is about people connecting online, for commerce, politics, and personal activities and communications, and we have already seen that enhances real-life relationships. Location-based social networking, in particular, will be a big part of our lives. Now we have the internet and high school sweethearts are reunited; strangers meet and form personal unions, Families are brought together. Adoptees find reunion, too. Interested groups thrive and businesses leap borders. Genealogies are learned, and one person in his lifetime can place himself into history, and comprehend his place in the span of time. On the internet, social alienation remains a factual force. But never before has a person had more opportunity for social integration. Social networking encourages people to have a greater number of much shallower friendships. Insofar as online interaction replaces real-world interaction, the internet is a negative force in the social world. Let's have some empirical glimpse collected from different age groups and professionals for research purpose in these regard.

A 56 years old businessman Razon, he started his business in 1998. But, from 2016, he started his business promotion using facebook. As he said 'buyers especially youths are depending more on online shopping. In most of the cases, they use facebook for buying where companies has online pages. Through that they can get many options to choose'. There is some contrasting thing happens to buyer's perception. Quote from Tonu (33) is important here-virtually demonstrated goods often are not similar like real one in terms of beauty, color and brightness too. Shopping using social media or facebook reduces interpersonal communication among buyers and traders that affect consumer relationship in contemporary society.

Uses of social media create many faceless relationships, sometimes it goes to love, romance and intimate bond too. Nowadays, with technology at our fingertips, having an affair sitting at home has become common phenomenon. One may not even know about one's spouse's affair because they may have perfected the art of lying. One of respondent said "I had a relationship with a girl. We introduced each other by facebook using fake ID." Most of these occur between strangers who might have never met and who become close to each other as they start to share intimate information. People start off as anonymous friends, kindle romances, which later may lead to adultery. These online faceless relationships sometimes make dangerous position of personal life. The criminals primarily 
target a man or a woman, and then they become facebook friend. Later, they developed relation with the targeted people. At one stage, they took their partners to a selected flat for unsocial activities. At that time, the members of the gang or criminals entered the flat, took their obscene photographs forcibly and collected money from them threatening to release the photos in social media.

Certainly both good things and bad have happened to relationships because of the internet [21] (Cummings, Butler, \& Kraut, 2002). The increasing ease of connection with people at a distance is improving social relations much more than the occasional gathering or thoughtless act is harming them. Some discretion about what to do and say online is necessary, but that's simply a social matter that needs to be worked out and understood - the tools are advancing quicker than the social etiquette around them. There will always be people who damage their relationships spectacularly, and if the internet were not available to them, they would do it another way. Based on the empirical data and research finding, Figure 1 will give us a glimpse understanding about how both private and public sphere has changed.

The social network provides a wide range of possible ways to build and further relationships with people around the world [22] (Castells, Materials for an Exploratory Theory of the Network Society, 2011). There's little question that the internet makes it easier to maintain relationships that might otherwise be severed by distance However, technology is a necessary, albeit not sufficient condition for the emergence of a new form of social organization based on networking,

\begin{tabular}{|l|l|l|l|l|}
\hline \multicolumn{8}{|c|}{ Nature of Activities Using Social Network and its' Impact } \\
\hline
\end{tabular}

Figure 1. Nature of activities using social network and its' impact (Source: fieldwork, 2018). 
that is on the diffusion of networking in all realms of activity on the basis of digital communication networks. This process can be likened to the role of electricity and the electrical engine in diffusing the organizational forms of the industrial society (e.g. the large manufacturing factory, and its correlate the labor movement) on the basis of new technologies of energy generation and distribution.

\section{Conclusions}

Bangladesh is a country where social and family bonding is used to be regarded most precious. Smartphone along with internet is now getting more preference, and working as destructive force. People around us sometimes are ignoring face-to-face conversation what make us socially disconnected in terms of real life communication and strengthening social ties. Social networking sites have been a phenomenal part of life, especially of the urban Bangladeshis. The structure of social networks affects the ways we live and work. And its positive aspect is that we are getting the opportunity to assemble a mass whenever any constructive social message or movement needs uproar. Social networking sites enable users to keep up with their friends and can decrease feelings of isolation. Creating a profile or home page enables creative expression and regular use of technology promotes competence. Social networking offers the opportunity to discuss school assignments or topics that may be more difficult to discuss in person.

These positives are counterbalanced by risks, however, such as sharing information with the wrong people or sharing much more than one might in person. Once the information is posted, it might not be possible to remove it, and inappropriate information could be problematic. Most of the urban dwellers, especially youths of Dhaka city, are getting more virtual rather than focusing on their real life activities. The study found these involvements with social networking and social media weakening real familial and social bond in the name of virtual connection.

\section{References}

[1] Houghton, D.J. and Joinson, A.N. (2010) Privacy, Social Network Sites, and Social Relations. Journal of Technology in Human Services, 28, 74-94. https://doi.org/10.1080/15228831003770775

[2] (2018) BTRC: Half of the Population Uses Internet. https://www.dhakatribune.com/bangladesh/2018/01/30/btrc-half-population-uses-i nternet/

[3] Halim, H.A. (2017) Only 2\% Active Facebook Users in Bangladesh. https://www.dhakatribune.com/feature/tech/2017/09/06/2-active-facebook-users-ba ngladesh/

[4] Rheingold, H. (2002) Smart Mobs: The Next Social Revolution. Perseus, Cambridge, MA.

[5] Anawati, D. and Craig, A. (2006) Behavioral Adaptation within Cross-Cultural Virtual Teams. IEEE Transactions on Professional Communication, 49, 44-56. https://doi.org/10.1109/TPC.2006.870459 
[6] Mortimore, P. (2001) Globalisation, Effectiveness and Improvement. School Effectiveness and School Improvement, 12, 229-249. https://doi.org/10.1076/sesi.12.2.229.3453

[7] Crimmins, E.M., Preston, S.H. and Cohen, B. (2010) International Differences in Mortality at Older Ages. National Academies Press (US), Washington DC.

[8] Kaul, V. (2012) Globalisation and Crisis of Cultural Identity. Journal of Research in International Business and Management, 2, 341-349.

[9] Robbins, R.H. (2008) Global Problems and the Culture of Capitalism. Pearson, Boston, MA.

[10] Ellison, N.B., Steinfield, C. and Lampe, C. (2007) The Benefits of Facebook "Friends": Social Capital and College Students' Use of Online Social Network Sites. Journal of Computer-Mediated Communication, 12, 1143-1168. https://doi.org/10.1111/j.1083-6101.2007.00367.x

[11] Watt, S.E., Lea, M. and Spears, R. (2002) How Social Is Internet Communication? A Reappraisal of Bandwidth and Anonymity Effects. In: Woolgar, S., Ed., Virtual Society? Oxford University Press, Oxford, 61-77.

[12] Chowdhury, M. (1996) Grameen Cyber Net Comes Forward to Provide Internet Service. Computer Jagat, 6, 36-37.

[13] Akhter, T. and Palit, A. (2016) Effects of Neoliberal Globalization on Readymade Garment Industry of Bangladesh: A Case Study for Chittagong. In: Das, R.C., Handbook of Research on Global Indicators of Economic and Political Convergence, IGI Global, 538-557 https://doi.org/10.4018/978-1-5225-0215-9.ch023

[14] Wuchty, S. (2009) What Is a Social Tie? PNAS: Proceedings of the National Academy of Sciences. https://www.ncbi.nlm.nih.gov/pmc/articles/PMC2741210/

[15] Donath, J. and Boyd, D. (2004) Public Displays of Connection. BT Technology Journal, 22, 71-82. https://doi.org/10.1023/B:BTTJ.0000047585.06264.cc

[16] (2017) Internet Usage Statistics. https://www.internetworldstats.com/stats.htm

[17] Ofcom (2008) Social Networking: A Quantitative and Qualitative Research Report into Attitudes, Behaviours and Use. Ofcom Office of Communications.

[18] Gefter, A. (2007) The Difference between "Real" and Online Is No Longer Clear-Cut. In: Engdahl, S., Ed., Online Social Networking, Greenhaven Press, Detroit.

[19] Miller, D. (2011) Tales from Facebook. Polity Books, Cambridge.

[20] Castells, M. (2006) The Network Society: From Knowledge to Policy. The Johns Hopkins University Press, Washington DC.

[21] Cummings, J.N., Butler, B. and Kraut, R. (2002) The Quality of Online Social Relationships. Communications of the ACM, 45, 103-108. https://doi.org/10.1145/514236.514242

[22] Castells, M. (2011) Materials for an Exploratory Theory of the Network Society. In: Kivisto, P., Ed., Social Theory: Roots and Branches, Oxford University Press, Inc., New York, 588-598. 